\title{
Libertad de prensa y derecho de los periodistas a mantener la confidencialidad de sus fuentes de información
}

\section{Press freedom and the right of journalists to keep the confidentiality of their information sources}

\author{
María-del-Mar Navas-Sánchez
}

Cómo citar este artículo:

Navas-Sánchez, María-del-Mar (2019). “Libertad de prensa y derecho de los periodistas a mantener la confidencialidad de sus fuentes de información". El profesional de la información, v. 28, n. 4, e280421.

https://doi.org/10.3145/epi.2019.jul.21

Artículo recibido el 10-11-2018

Aceptación definitiva: 26-04-2019

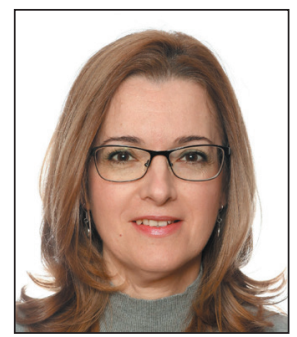

María-del-Mar Navas-Sánchez

https://orcid.org/0000-0002-8112-1706

Universidad de Málaga

Campus de Teatinos, $\mathrm{s} / \mathrm{n}$.

29071 Málaga, España

navas@uma.es

\section{Resumen}

A pesar de su importancia para las libertades de expresión, información y prensa y de estar comúnmente aceptado el derecho de los periodistas a mantener en secreto la identidad de sus fuentes de información [art. 20.1.d) CE] aún persisten, sin embargo, ciertas sombras e incertidumbres en torno a este derecho, susceptibles de generar en la práctica situaciones de una gran inseguridad jurídica para los profesionales de la información. Subsanables, sin embargo, si volvemos nuestra mirada a Europa, a la jurisprudencia del TEDH, como nos obliga, por lo demás, el art. 10.2 CE. A través de un recorrido por las principales sentencias de este Tribunal sobre esta cuestión (desde Goodwin contra Reino Unido hasta la reciente Big Brother Watch y otros contra Reino Unido) se sistematizan en este trabajo los rasgos principales que caracterizan al secreto periodístico en esta jurisprudencia y que resultan, por tanto, también de aplicación en España.

\section{Palabras clave}

Secreto periodístico; Fuentes de información; Confidencialidad de las fuentes; Libertad de expresión; Derecho a la información; Libertad de prensa; Derecho al secreto profesional; Periodistas; Tribunal Europeo de Derechos Humanos; Chilling effect; "Perro guardián” de la democracia.

\section{Abstract}

Despite its importance for the freedoms of expression, information and press, and the fact that is commonly accepted the right of journalists to keep the identity of their sources of information secret [art. 20.1.d) Spanish Constitution] certain shadows and uncertainties remain about this right, which may generate situations of great legal uncertainty in

\footnotetext{
Financiación

Investigación enmarcada dentro de los proyectos:

Límites a la fragmentación de los derechos fundamentales en la Europa integrada y un contexto globalizado: sujetos, ordenamientos, competencias, estándares y territorios (DER2017-85659-C5-4-R, Feder/Ministerio de Ciencia, Innovación y Universidades - Agencia Estatal de Investigación);

La influencia de la audiencia en la innovación periodística y gestión de la participación: riesgos y oportunidades (CSO2015-64955-C4-3-R, Mineco-Feder).
} 
practice for journalists. They can be, however, overcome, if we turn our attention to Europe, to the jurisprudence of the $E C H R$, as we are obliged, on the other hand, by art. 10.2 EC. Through an analysis of the main judgments of the ECHR on this issue (from Goodwin versus the United Kingdom to the recent Big Brother Watch and others versus the United Kingdom), in this work are systematized the main features that define this European protection of the confidentiality of the sources. They are also applicable in Spain.

\section{Keywords}

Journalistic secret; Information sources; Confidentiality of the sources; Freedom of expression; Press freedom; Journalists; Information sources protection; European Court of Human Rights; Chilling effect; Watchdog role of the democracy; Spain.

\section{Libertades de expresión e información y secreto periodístico}

Está fuera de toda discusión y no requiere mayor argumentación el que las libertades de información y expresión resultan esenciales en cualquier sistema democrático, del que forman parte indisoluble. A ello se han referido tanto el Tribunal Constitucional español (en adelante, TC) como el Tribunal Europeo de Derechos Humanos (en adelante, TEDH o el Tribunal). El primero, ya en unas de sus primeras sentencias afirma que:

“El artículo 20 de la Constitución, en sus distintos apartados, garantiza el mantenimiento de una comunicación pública libre, sin la cual quedarían vaciados de contenido real otros derechos que la Constitución consagra, reducidas a formas hueras las instituciones representativas y absolutamente falseado el principio de legitimidad democrática (...) que es la base de toda nuestra ordenación jurídico-política" (STC 6/1981).

De manera incluso más gráfica el TEDH, al calificar a la prensa como "perro guardián" (vital public watchdog role of the press) de la democracia, justamente para enfatizar la importancia de su función informativa, vigilante y fiscalizadora ${ }^{1}$.

Ahora bien, en no pocas ocasiones el que la prensa pueda cumplir con esta función que le es propia e informar sobre asuntos veraces y de interés general, va a depender de que lleguen a conocimiento del periodista ciertas informaciones que están ocultas o son secretas o confidenciales, o que sólo resultan accesibles para ciertas personas que son justamente quienes las ponen a su disposición. EI TEDH consciente ya desde muy pronto de la importancia que la protección de estas fuentes informativas tiene para la propia realización de las libertades de expresión, información y prensa, no ha dudado en entenderla incluida bajo la cobertura que el Convenio Europeo de Derechos Humanos (en adelante, CEDH o el Convenio) otorga a la libertad de expresión (art. $10 \mathrm{CEDH}$ ). Ello a pesar de que el CEDH no se refiere expresamente a la protección de las fuentes periodísticas, lo que no ha sido óbice, sin embargo, para que el TEDH haya entendido desde su más temprana jurisprudencia (asunto Goodwin contra Reino Unido, STEDH de 27 de marzo de 1996) que la libertad de expresión consagrada en el art. 10 CEDH comprende y garantiza asimismo el derecho de los periodistas a mantener en secreto la identidad de sus fuentes de información.

El secreto profesional de los periodistas o secreto periodístico forma así parte esencial de la libertad de expresión. Entendiendo esta libertad en el sentido amplio en que lo hace el CEDH, como comprensivo asimismo de la libertad de información, esto es, del derecho a comunicar y recibir libremente información veraz. Si esto es así en el ámbito europeo, con más razón aún cabe afirmarlo respecto del ordenamiento jurídico español en el que el secreto profesional de los periodistas goza de un explícito reconocimiento constitucional como un auténtico derecho fundamental en el art. 20.1.d) $C E$, de acuerdo con el cual:

"Se reconoce y protege el derecho a recibir y comunicar libremente información veraz por cualquier medio de difusión. La ley regulará el derecho a la cláusula de conciencia y al secreto profesional en el ejercicio de estas libertades".

De este modo, y aunque se hable genéricamente de su relación con la libertad de expresión, el secreto profesional de los periodistas aparece, tanto en su configuración española como europea, íntimamente vinculado al

El secreto profesional de los periodistas o secreto periodístico forma parte esencial de la libertad de expresión derecho a informar y ser informados sobre asuntos de interés general. Pero no en puridad, a la libertad de expresión en sentido estricto o libertad de expresar pensamientos, ideas, opiniones que no requieren de fuente alguna que proporcione la información sobre la que fundamentar la opinión o idea.

Por lo demás, la razón de ser de esta protección -ya sea explícita, como sucede con la Constitución o implícita, en el caso del $C E D H$ - es la de hacer posible la realización efectiva de las libertades de información, expresión (entendida en el sentido amplio a que ya se ha hecho referencia) y prensa. Como ya destacó el TEDH en el asunto Goodwin contra Reino Unido antes citado, la ausencia de esta protección

"podría disuadir a las fuentes periodísticas de ayudar a la prensa a informar al público sobre cuestiones de interés general. En consecuencia, la prensa podría ser menos capaz de jugar su papel indispensable de "perro guardián" y su aptitud para suministrar informaciones precisas y fiables podría encontrarse reducida". 
El secreto periodístico deviene así en un derecho instrumental (Fernández-Miranda-Campoamor, 1990) o en una garantía institucional (STC 24/2019) para la protección de un interés que trasciende tanto al de la propia fuente en que no se desvele su identidad como al del periodista que se acoge al secreto profesional, para afectar al conjunto de la sociedad, incidiendo directamente en el derecho de los ciudadanos a ser informados de los asuntos de interés general que les conciernen, también cuando estas informaciones son proporcionadas por fuentes anónimas [Financial Times Ltd y otros contra Reino Unido (STEDH 15 diciembre 2009); Sanoma Uitgevers B.V. contra Holanda (Sanoma II) (STEDH 14 de septiembre de 2010)].

Es por ello que el TEDH ha calificado reiteradamente este derecho de los periodistas como "piedra angular" de la libertad de expresión. Y que a la postre ha resultado esencial para el fortalecimiento mismo de las libertades de información y expresión en el conjunto de los estados miembros del Consejo de Europa (Voorhoof, 2009).

"La protección de las fuentes periodísticas es una de las piedras angulares de la libertad de prensa (...). La ausencia de tal protección podría disuadir a las fuentes periodísticas de ayudar a la prensa a informar al público sobre cuestiones de interés general. En consecuencia, la prensa podría ser menos capaz de jugar su papel indispensable de "perro guardián" y su aptitud para suministrar informaciones precisas y fiables podría encontrarse reducida. Teniendo en cuenta la importancia que reviste la protección de las fuentes periodísticas para la libertad de la prensa en una sociedad democrática y el efecto negativo sobre el ejercicio de esta libertad que podría producir una resolución de divulgación, tal medida únicamente podría conciliarse con el artículo 10 del Convenio si estuviera justificada por un imperativo preponderante de interés público" (STEDH de 27 de marzo de 1996, caso Goodwin contra Reino Unido).

A pesar de su importancia, la situación jurídica de este derecho es muy diferente según se trate del ámbito europeo (CEDH y jurisprudencia del TEDH) o español. Mientras que en Europa el derecho al secreto periodístico se encuentra más que suficientemente definido gracias a la labor del TEDH, en el ordenamiento español sucede justamente lo contrario.

EI TEDH ha desempeñado un papel clave en el reconocimiento, fortalecimiento y configuración del régimen jurídico del derecho de los periodistas al secreto profesional. Desde el asunto Goodwin contra Reino Unido hasta la reciente sentencia dictada en el caso Big Brother Watch y otros contra el Reino Unido (STEDH de 13 de septiembre de 2018) han sido numerosas las ocasiones en las que este Tribunal se ha ocupado de aspectos relevantes del secreto periodístico. Desde quienes pueden ser consideradas fuentes periodísticas y, por tanto, objeto de protección, hasta los requisitos que debe cumplir cualquier entrada, registro o decomiso de la documentación, dispositivos o materiales de trabajo de un periodista, pasando por afirmar que la protección no sólo tiene lugar cuando las fuentes son anónimas o desconocidas para la policía o el juez, sino incluso cuando éstos ya conocen su identidad, pero se requiere al periodista que desvele otros datos relativos al o los contactos (modo, duración, frecuencia) con su fuente (STEDH de 5 de octubre de 2017, asunto Becker contra Noruega). E incluso por condenar al Reino Unido por el modo en que regulaba una de las medidas más ampliamente utilizadas por los Estados en la lucha contra el terrorismo: la vigilancia masiva de las comunicaciones, por entender el Tribunal que no protegía adecuadamente la confidencialidad de las fuentes periodísticas ante la eventualidad de que esta medida indiscriminada pudiera afectar a las comunicaciones de quienes son profesionales de la información (Big Brother Watch y otros contra Reino Unido).

Distinta es por el contrario la situación en España. Cierto es que también está comúnmente admitido el derecho de los periodistas a no desvelar sus fuentes de información (Villaverde-Menéndez, 2009), lo que no podía suceder de otro modo dado su reconocimiento al máximo nivel constitucional. La escasa litigiosidad y el normalmente corto recorrido judicial de estos asuntos que suelen fenecer en primera instancia puede ser visto como un reflejo de esta generalizada aceptación. Pero esto no ha impedido sin embargo que se produzcan ciertas situaciones en las que el secreto periodístico puede verse en entredicho. Por ejemplo, que un periodista, llamado como testigo en un proceso penal, sea requerido para que desvele ciertos datos relativos a su fuente o al modo en que obtuvo la información publicada². $\mathrm{O}$ algo en absoluto infrecuente, que un profesional de la información se vea, a raíz de la publicación de cierta noticia, investigado o encausado, normalmente por un delito de revelación de secretos ${ }^{3}$, e incluso condenado ${ }^{4}$. Ni que las oficinas de un periódico hayan sido objeto de un registro ordenado judicialmente con el propósito de averiguar los datos relativos a las fuentes de información, y los móviles de los periodistas requisados con la misma finalidad ${ }^{5}$. 
Como tampoco implica que no existan y persistan ciertas dudas e inseguridades, incluso en torno a aspectos básicos y esenciales de esta institución del secreto profesional de los informadores y de su aplicabilidad en la práctica. Sirva como muestra de esto último las siguientes consideraciones contenidas en una de las resoluciones judiciales dictadas en el asunto Tellería, donde se afirmaba, respecto del secreto periodístico, que se trata de "una cuestión compleja" respecto de la cual

"existen amplios márgenes de incertidumbre (...) como son los referentes a la titularidad del derecho, las facultades que confiere a su titular y los límites que pueden oponerse el mismo" (Auto del Juzgado de Instrucción número 2 de Vitoria, de 27 de septiembre de 2010).

\section{ATAQUE A LA LIBERTAD DE EXPRESION}

\section{\#El SecretoNoSeToca: Los periodistas se concentran en Palma y viralizan sus protestas}

\author{
Más de cien personas se concentran en Cort en defensa del derecho al secreto \\ profesional y contra la incautación de material periodístico - Profesionales de la \\ información de todo el país se fotografían tapando sus bocas y mostrando sus móviles \\ en señal de apoyo \\ Nair Cuéllar Europa Press Palma | 14.12.2018 | 00:40
}

https://www.diariodemallorca.es/mallorca/2018/12/14/secretonosetoca-periodistasconcentran-palma/1374812.html

En definitiva, existen y persisten ciertas dudas e inseguridades sobre todo lo que define y da sentido al derecho al secreto profesional de los periodistas (quién está protegido, de qué forma lo está y frente a qué amenazas y riesgos).

Precisamente con el propósito de contestar a estas cuestiones, contribuyendo así a clarificar y a definir el alcance, ámbito de aplicación y régimen jurídico de este derecho de los periodistas nace este trabajo, lo que requiere, antes de nada, recordar que en España no existe una ley reguladora del secreto profesional de los periodistas. Sin que tampoco dispongamos de una jurisprudencia significativa de nuestros máximos tribunales (preferentemente del TC o, en su defecto, del Tribunal Supremo), a partir de la cual configurar en detalle este derecho, susceptible, en consecuencia, de suplir esa ausencia de regulación.

Esto no significa en modo alguno no ya que los periodistas no puedan acogerse a este derecho (el art. 53.1 CE impone su aplicabilidad directa), sino tampoco que no exista un modelo de secreto periodístico aplicable también en nuestro ordenamiento jurídico. Implica tan sólo que no existe un modelo propio. Esta sería la primera de las premisas sobre las que se sustenta este trabajo. En otras palabras, entendemos que el legislador, con su inactividad, ha renunciado a configurar, a partir de las previsiones contenidas en el art. 20.1.d) $C E$, el derecho al secreto periodístico con un régimen jurídico propio, dotándolo de sus propias particularidades e idiosincrasias. Pero tal modelo existe, sólo que no es obra de nuestro legislador y/o jurisprudencia constitucional u ordinaria, sino del TEDH. En efecto, de la ya abundante jurisprudencia dictada por el TEDH en relación con la protección de las fuentes de información cabe deducir un auténtico régimen jurídico del derecho de los periodistas a no desvelar la identidad de sus fuentes. Además, y ésta sería la segunda de las premisas, sostenemos que acudir a esta jurisprudencia europea para suplir este déficit de legislación y jurisprudencia propias no es sólo una cuestión de mera oportunidad (esa jurisprudencia europea existe y es fácilmente accesible), sino que se trata de una verdadera obligación jurídico-constitucional que deriva directamente del art. 10.2 CE. De acuerdo con el cual,

"Las normas relativas a los derechos fundamentales y a las libertades que la Constitución reconoce se interpretarán de conformidad con la Declaración Universal de Derechos Humanos y los tratados y acuerdos internacionales sobre las mismas materias ratificados por España".

Entre los cuales ocupa un lugar preferente el CEDH en el modo en que ha sido interpretado por el TEDH.

Por tanto, no se trata sólo de que, en ausencia de otros referentes internos o externos, los distintos implicados (periodistas, policía, jueces y fiscales) puedan -como de hecho hacen ${ }^{6}$ - al igual que la doctrina (Lazkano-Brotóns, 2004; Moretón-Toquero, 2014) acudir a la jurisprudencia del TEDH para dotar de contenido a nuestro derecho fundamental al secreto periodístico, sino que entendemos que necesariamente deben hacerlo. O lo que es lo mismo, dado que la obligación que deriva del art. 10.2 CE es una obligación de resultado (Queralt-Jiménez, 2008; Saiz-Arnaiz, 2009), la protección que apliquen las instituciones al periodista que decida acogerse al secreto profesional deberá ser sustancialmente conforme, en el sentido de equivalente, a la que deriva de las resoluciones del TEDH.

De este modo, aunque probablemente hoy la existencia de una ley específica reguladora del secreto periodístico ofrecería más ventajas que inconvenientes a los periodistas -particularmente, seguridad jurídica- entendemos que no es imprescindible. Cierto es que la inexistencia de esta ley ha sido en buena medida defendida y propiciada por el propio sector profesional, bastante reacio, si no frontalmente opuesto, a cualquier intento de regulación legislativa, que ha visto en la falta de tal ley más una ventaja que un inconveniente, en el entendimiento de que cualquier intento de regulación iba a suponer más una limitación o restricción del propio derecho que una garantía para el mismo (CEC, 1988; Fernández-Miranda-Campoamor, 1990). 
La realidad ha demostrado que este vacío legislativo no siempre juega necesariamente a favor de los periodistas. La actuación del juez en el caso Cursach ofrece un buen ejemplo de ello. Además, es preciso destacar que a estas alturas no se trataría ya de cualquier ley del secreto profesional de los periodistas, como si el legislador dispusiese de un amplio margen para decidir cómo regularlo. Antes al contrario, dada la obligación que deriva del art. 10.2 CE y que el régimen jurídico de este derecho está bastante definido en la jurisprudencia del TEDH, las opciones del legislador a la hora de apartarse de este modelo consolidado de secreto periodístico son más bien pocas. Sólo admisibles en la medida en que supongan una mejora respecto del estándar de protección -ya de por sí ciertamente elevado- que deriva de la jurisprudencia europea.

En cualquier caso, exista o siga sin existir tal ley, lo que sí estimamos sumamente recomendable es que este modelo, tal y como deriva de la jurisprudencia del TEDH y resulta de aplicación también en el ordenamiento jurídico español, sea conocido por todos. Con la finalidad de contribuir a ello, procederemos a continuación a abordar los aspectos más relevantes del mismo, sistematizando para ello las principales sentencias del TEDH.

\section{Titular del derecho al secreto periodístico}

A pesar de que la finalidad de este derecho es proteger la confidencialidad de la fuente informativa, no es ésta el sujeto activo del mismo, sino el profesional de la información. En efecto, titular del derecho al secreto periodístico es el periodista al que la fuente ha proporcionado la información. Este es el sujeto principal y primordialmente protegido por el ordenamiento a través de este derecho. Ahora bien, no se trata de una protección generalizada e indiscriminada, a modo de privilegio del periodista, sino de una muy concreta y específica en el entendimiento de que al protegerlo se está protegiendo simultáneamente a las libertades de información y prensa y a la posibilidad misma de que existan fuentes informativas. Por eso el derecho consiste justamente en la facultad que se otorga al periodista de negarse a desvelar la identidad de su fuente sin que pueda sufrir sanción o perjuicio alguno por ello. Además, dada su naturaleza jurídica de derecho o facultad (Fernández-Miranda-Campoamor, 1990; Carrillo, 1993; Otero-González, 2001; Moretón-Toquero, 2012; 2014), no existe un correlativo deber por parte del periodista de guardar silencio sobre tal identidad, quien podrá si así lo estima oportuno, hacerla pública. Podrá existir, y de hecho así se plasma en la mayoría de los códigos deontológicos, una obligación ética al respecto para el periodista ${ }^{7}$, incluso jurídica si así lo han pactado el periodista y su fuente, pero que no derivará en todo caso de la propia naturaleza y razón de ser de este tipo de secreto profesional, el de los periodistas, sino del acuerdo contractual entre ambos implicados ${ }^{8}$.

Esto no significa que la fuente quede totalmente desprotegida, pero sí que la protección que el ordenamiento jurídico le otorga a través del secreto profesional es tan sólo indirecta, a través del periodista al que la fuente ha facilitado la información. Y además en ningún caso, como acabamos de ver, absoluta, ya que depende de que el periodista efectivamente se acoja al secreto profesional, lo que por otra parte suele ser lo habitual.

\section{Objeto de protección del derecho al secreto profesional de los periodistas}

La fuente no es pues titular del derecho al secreto periodístico, pero sí que es su objeto. Más concretamente, lo que se protege a través de este derecho es la identidad de la fuente. De ahí deriva ya inmediatamente una diferencia sustancial con otros tipos de secretos profesionales que también pueden ser objeto de reconocimiento y protección por el derecho. En nuestro caso, por ejemplo, el que incumbe a los abogados (art. 24 CE) o a los médicos, entre otros profesionales. En estos casos, lo protegido no es quién proporciona la información al profesional, sino la información misma, su contenido. En el ámbito periodístico por el contrario, el contenido (la información) está por definición llamado a ser divulgado, a ser puesto a disposición de todos (Fernández-Miranda-Campoamor, 1990; Carrillo, 1993), previa reelaboración en su caso por el periodista, para su público conocimiento. Por eso el derecho no protege la información conocida por el periodista gracias a su relación con la fuente, sino la identidad de esta última, de la persona que le proporcionó dicha información.

Ello plantea a su vez dos cuestiones:

- quiénes pueden ser consideradas "fuentes";

- qué ha de entenderse por su "identidad".

Ambas resueltas por el TEDH de un modo ciertamente generoso y favorable para el secreto periodístico y, por tanto, también para las libertades comunicativas (información, expresión y prensa).

Para la primera de estas cuestiones, el TEDH ha seguido lo dispuesto en la Recomendación $n$ o $R$ (2000) 7 sobre el derecho de los periodistas a no desvelar sus fuentes de información". Lo que le ha llevado a establecer que "cualquier persona que proporciona información a un periodista" es una "fuente" periodística y, por tanto, ha de entenderse incluida dentro del ámbito de protección de este derecho (Telegraaf Media Nederland Landelijke Media B.V. y otros contra Holanda, STEDH de 22 de noviembre de 2012). Pero siempre que se trate de fuentes en el sentido genuino del término, esto es, cuando su finalidad es ayudar o asistir a la prensa a informar sobre asuntos de interés general que los ciudadanos tienen derecho a conocer. No así cuando la pretendida fuente lo que busca es utilizar a la prensa y la protección que el ordenamiento otorga a las fuentes periodísticas, mediante la garantía de su anonimato, para eludir su propia responsabilidad penal (Stichting Ostade Blade against The Netherlands, Decisión del TEDH de 27 de mayo de 2014). 
De la misma manera y siguiendo también aquí la Recomendación antes mencionada, el TEDH ha entendido que la protección se refiere por supuesto a la información que sirve directamente para identificar a la fuente, como serían sus datos personales. Pero no sólo a ella, sino también en la medida en que puedan dar lugar a su identificación, a la relativa al modo en que el periodista obtuvo la información e incluso,

"la parte no publicada de la información proporcionada por la fuente al periodista".

Así lo ha afirmado entre otros, siguiendo el criterio sentado en el asunto Telegraaf antes citado, en la STEDH de 18 de abril de 2013 dictada en el asunto Saint-Paul Luxembourg S.A. contra Luxemburgo. En la medida en que esta información pueda conducir a la identificación de la fuente, el periodista puede legítimamente, amparándose en el secreto periodístico, negarse a facilitarla.

Además, esta concepción amplia y garantista que el TEDH tiene sobre esta institución del secreto periodístico le ha llevado a entender asimismo protegidos por este derecho tanto los materiales como los soportes e instrumentos de trabajo del periodista [Financial Times Ltd y otros contra Reino Unido; Sanoma Il y Nagla contra Lituania (STEDH de 16 de julio de 2013)]. Tales como sus notas, grabaciones, fotografías, documentos, ordenadores o dispositivos externos de almacenamiento (discos duros, tarjetas de memoria, memorias USB...). Se viene a confirmar así la concepción amplia que sobre el objeto del derecho al secreto periodístico se tenía ya en la doctrina constitucionalista española (Fernández-Miranda-Campoamor, 1990; Carrillo, 1993), pero que el TEDH lleva incluso más allá al extenderlo también a las comunicaciones, domicilio y lugares de trabajo de los profesionales de la información.

\section{Ampliación del objeto: la protección reforzada frente a registros e intervención de las comunicaciones de los periodistas}

No sólo la identidad de las fuentes, los materiales, soportes e instrumentos de trabajo del periodista están protegidos por el secreto profesional, sino que el TEDH ha entendido que esta protección abarca también al domicilio, lugares de trabajo y comunicaciones del profesional de la información.

Para valorar la importancia de esta protección ampliada es preciso tener en cuenta que el domicilio, los lugares de trabajo y las comunicaciones del periodista -como las de cualquier otra persona- ya están protegidas a través de otros derechos, diferentes del secreto profesional. En el caso del domicilio y las comunicaciones simultáneamente en ambos ordenamientos, constitucional y europeo. Así, ambos son objeto de protección tanto a través de nuestros derechos fundamentales a la inviolabilidad del domicilio (art. 18.2 CE) y al secreto de las comunicaciones (art. 18.3 CE) como mediante el derecho a la protección de la vida privada, domicilio y correspondencia recogido en el art. 8 CEDH. Por el contrario, los locales de trabajo-la oficina del periódico- sólo estarían claramente protegidos mediante el art. $8 \mathrm{CEDH}$, siendo más dudosa la aplicación del art. 18.2 CE, dada la interpretación restrictiva que nuestro TC ha hecho de la noción "domicilio".

Como estos espacios y aspectos de la vida privada de cualquier persona -incluidos los periodistas- ya están protegidos, cabe preguntarse qué sentido tiene entonces su salvaguarda también a través del derecho al secreto profesional cuando se trata específicamente de periodistas. La respuesta es sencilla: reforzar esta protección, lo que se va a reflejar asimismo, como veremos más adelante, en la adición de una garantía cuando se trata del registro y decomiso de materiales periodísticos: su control judicial previo. Esto es, sólo un juez o en todo caso una autoridad independiente -no la policía- podrá acordarla y verificar su correcta ejecución cuando se trate de periodistas. Se viene a poner así en valor la trascendental importancia que para la libertad de expresión tiene la protección de las fuentes informativas.

Con el secreto periodístico no se trata ya de proteger genéricamente la vida privada, comunicaciones y domicilio del periodista, sino algo diferente: sus fuentes de información. ¿Cómo? Evitando que estas actuaciones (interceptación de las comunicaciones; entrada, registro e incautación de documentación, soportes y/o instrumentos de trabajo del periodista), en principio absolutamente legítimas si se adoptan y ejecutan conforme a la ley, puedan ser utilizadas para conocer la identidad de la persona que proporcionó al periodista la información controvertida, conculcando así el derecho del profesional de la información a no desvelar quién es su fuente. Porque como ha señalado el TEDH, con independencia de que con tales medidas se pueda afectar también a los derechos antes aludidos, lo que sin duda alguna sí que hay cuando de un periodista se trata, es una injerencia -incluso lesión- de su derecho a mantener en secreto sus fuentes informativas (STEDH de 27 de noviembre de 2007, asunto Tillack contra Bélgica).

Es más, el TEDH ha destacado en numerosas ocasiones que en estos casos la injerencia en el secreto periodístico es incluso más grave que el mero requerimiento o la orden policial o judicial dada al periodista para que desvele directamente la identidad de su fuente [Roemen y Schmit contra Luxemburgo (STEDH de 25 de febrero de 2003); Ernst y otros contra Bélgica (STEDH de 15 de julio de 2003); Nagla contra Lituania; Görmüs y otros contra Turquía (STEDH 19 de enero 
de 2016)]. La razón es muy sencilla: una medida de este tipo potencialmente da a los investigadores (jueces, policía) acceso a toda la documentación que obra en poder de los periodistas [Ressiot y otros contra Francia (STEDH de 28 de junio de 2012)].

La protección del domicilio, lugares de trabajo y comunicaciones del periodista deviene así en instrumental para garantizar la confidencialidad de las fuentes periodísticas y, por tanto, para hacer posible la realización de las libertades de expresión e información. Se trata además de una protección que en un contexto como el actual, progresivamente más digital, está llamado a desempeñar un papel cada vez más relevante y esencial, especialmente por lo que se refiere a la protección de las comunicaciones del periodista con sus fuentes, tal y como ha llamado la atención recientemente la Unesco [(2017) Protecting journalism sources in the digital age $]^{10}$ y se ha puesto de manifiesto en el asunto Big Brother Watch y otros contra Reino Unido.

Es preciso destacar que, de acuerdo con el TEDH, para que opere esta protección adicional que el secreto periodístico aporta al domicilio y lugares de trabajo del periodista no es necesario que quede acreditado de manera indubitada que la finalidad del registro e incautación era averiguar la identidad de la fuente. Basta con que tales medidas, por el modo amplio, vago o indiscriminado en que fueron autorizadas o ejecutadas, no excluyan tal posibilidad (Saint-Paul Luxembourg S.A. contra Luxemburgo) de conocer la identidad de la fuente en cuestión o, incluso, la de otras fuentes del periodista (Nagla contra Lituania). En estos casos, la falta de proporcionalidad de este tipo de actuaciones determina per se y de modo automático su ilegitimidad y, por tanto, la lesión del derecho al secreto periodístico.

En esta misma línea garantista de la jurisprudencia del TEDH resulta que esta protección tiene lugar cualquiera que haya sido el resultado del registro. También, aunque haya sido infructuoso o incluso si no se han iniciado acciones judiciales contra la fuente por la filtración. Lo determinante en estos casos resulta ser el efecto disuasorio (chilling effect) que medidas de este tipo pueden tener sobre las fuentes actuales o potenciales. Tal y como afirma el TEDH en el asunto Sanoma II:

\begin{abstract}
"cada vez que parece que los periodistas han contribuido a la identificación de las fuentes anónimas, se produce un efecto disuasivo",
\end{abstract}

susceptible de inhibir a las posibles fuentes de proporcionar a los periodistas la información que éstos necesitan para informar a la ciudadanía sobre asuntos de interés general.

En relación con las comunicaciones del periodista, el TEDH se ha referido expresamente a aquellos casos en los que la interceptación del periodista no lo ha sido como consecuencia de una medida individualizada, dirigida a interceptar directamente las comunicaciones de ese periodista en concreto, sino como resultado de una operación de vigilancia e interceptación masiva de comunicaciones (Weber and Saravia contra Alemania, Decisión del TEDH de 29 de junio de 2006; Big Brother Watch y otros contra Reino Unido), afirmando que en estos casos la mera interceptación -como paso previo a acceder a su contenido- no

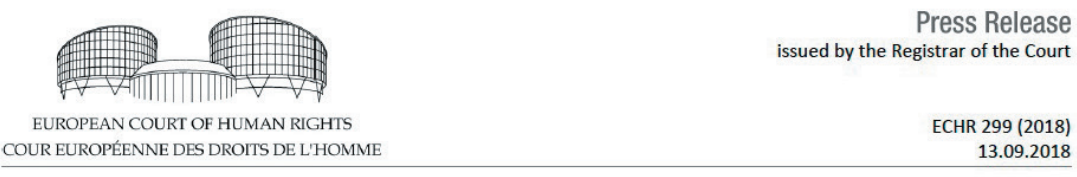

Some aspects of UK surveillance regimes violate Convention

The case of Big Brother Watch and Others v. the United Kingdom (applications nos. 58170/13, $62322 / 14$ and $24960 / 15$ ) concerned complaints by journalists and rights organisations about three different surveillance regimes: (1) the bulk interception of communications; (2) intelligence sharing with foreign governments; and (3) the obtaining of communications data from communications service providers.

Both the bulk interception regime and the regime for obtaining communications data from communications service providers have a statutory basis in the Regulation of Investigatory Powers Act 2000. The Investigatory Powers Act 2016, when it comes fully into force, will make significant changes to both regimes. In considering the applicants' complaints, the Court had regard to the law in force at the date of its examination. As the provisions of the IPA which will amend the regimes for the bulk interception of communications and the obtaining of communications data from communications service providers were not in force at that time, the Court did not consider them in its assessment.

In today's Chamber judgment ${ }^{1}$ the European Court of Human Rights held, by five votes to two, that: the bulk interception regime violated Article 8 of the European Convention on Human Rights (right to respect for private and family life/communications) as there was insufficient oversight both of the selection of Internet bearers for interception and the filtering, search and selection of intercepted communications for examination, and the safeguards governing the selection of "related communications data" for examination were inadequate.

In reaching this conclusion, the Court found that the operation of a bulk interception regime did not in and of itself violate the Convention, but noted that such a regime had to respect criteria set down in its case-law.

The Court also held, by six votes to one, that:

the regime for obtaining communications data from communications service providers violated Article 8 as it was not in accordance with the law; and

that both the bulk interception regime and the regime for obtaining communications data from communications service providers violated Article 10 of the Convention as there were insufficient safeguards in respect of confidential journalistic material.

It further found that the regime for sharing intelligence with foreign governments did not violate either Article 8 or Article 10.

The Court unanimously rejected complaints made by the third set of applicants under Article 6 (right to a fair trial), about the domestic procedure for challenging secret surveillance measures, and under Article 14 (prohibition of discrimination).

For an FAQ on the judgment please click here. 
supone una afectación particularmente grave del derecho a mantener la confidencialidad de las fuentes. Aquí resulta determinante para el Tribunal que la finalidad de esta interceptación indiscriminada no es precisamente la de conocer la identidad de las fuentes periodísticas, sino otra diferente, normalmente relacionada con la prevención del terrorismo. No obstante, incluso siendo esto así, el Tribunal ha establecido que son necesarias una serie de garantías adicionales ante la eventualidad de que pueda afectar a las comunicaciones de periodistas. Entre ellas, ha exigido que exista una supervisión independiente de los criterios de búsqueda, selección y acceso a las comunicaciones interceptadas, precisamente para limitar la posibilidad misma de interceptar tales comunicaciones de los periodistas, así como de acceder a las mismas una vez que las del periodista han sido incluidas entre aquellas que finalmente van a ser objeto de investigación. Todo ello con el objetivo de salvaguardar la confidencialidad de las fuentes, y además, no sólo cuando se trata de acceder a lo comunicado (a su contenido) sino también cuando se trata de los denominados datos de la comunicación o metadatos (Big Brother Watch y otros contra Reino Unido).

\section{Límites al secreto periodístico. Cuándo y cumpliendo qué requisitos pueden las autoridades conocer la identidad de las fuentes periodísticas}

Dada la importancia del secreto periodístico ¿cabe entender que se trata de un derecho absoluto, que ha de prevalecer siempre cualquiera que sea el derecho enfrentado y, por tanto, con independencia de cuál sea el interés que opone la otra parte por conocer la identidad de la fuente? En absoluto. Como cualquier otro derecho también éste es un derecho sujeto a ciertos límites. Susceptible por tanto de verse privado de eficacia en la práctica cuando se estima que, en el caso concreto, el derecho o interés contrapuesto enfrentado es digno de una mayor protección. Pero para ello deberá cumplirse a su vez una serie de requisitos.

Efectivamente, obligar a un periodista a que desvele en contra de su voluntad la identidad de sus fuentes, supone una clara injerencia en su derecho y por tanto una limitación del mismo. Ello, tanto si se trata de una orden directa de las autoridades (policía, juez) como si éstas tratan de conocer ese dato de manera indirecta, mediante el registro e incautación de su documentación y/o instrumentos de trabajo o de la vigilancia e interceptación de sus comunicaciones. Es por ello que siguiendo la doctrina del TEDH, para que tal orden o medida pueda ser legítimamente dada o adoptada conforme a Derecho, necesariamente ha de cumplir los requisitos establecidos en el art. $10.2 C E^{11}$. A saber, es necesario que la medida en cuestión:

- esté prevista en la Ley;

- persiga una finalidad legítima -entendiendo por tal sólo las expresamente previstas en el citado art. 10.2 (Lazkano-Brotóns, 2015)-;

- resulte necesaria en una sociedad democrática.

Esto último implica a su vez que la limitación ha de resultar proporcional a la finalidad pretendida y que las razones dadas por las autoridades para justificar su adopción han de resultar no sólo pertinentes, sino también suficientes debido a la importancia del derecho sacrificado: el secreto profesional de los periodistas y por extensión, la libertad de prensa. Además, hay que tener en cuenta que ya desde el asunto Goodwin contra Reino Unido el TEDH ha afirmado que los Estados disponen de un escaso margen de apreciación cuando tratan de limitar la confidencialidad de las fuentes periodísticas.

Ello ha llevado a este Tribunal a ser particularmente estricto a la hora de examinar las limitaciones impuestas al secreto periodístico, especialmente, como veremos dada su mayor lesividad potencial, cuando se trata del registro del domicilio o lugar de trabajo del periodista y/o incautación de los materiales e instrumentos de trabajo allí encontrados.

Así ha establecido que la confidencialidad de las fuentes periodísticas sólo debe ceder cuando conocer la identidad de quien ha proporcionado la información al periodista resulte imprescindible para alcanzar alguno de los fines a que se refiere el art. 10.2 CEDH. Singularmente para evitar la divulgación de información que es y debe seguir siendo confidencial, particularmente cuando afecta a la seguridad nacional. O cuando se erige en el único medio válido y eficaz para prevenir o castigar la posible comisión de unos hechos delictivos. Por ejemplo, en relación con el delito en que haya podido incurrir la propia fuente al filtrar la información confidencial al periodista. Pero en ningún caso resultaría legítima cuando conocer tal identidad persigue otros propósitos diferentes o cuando se revela como un fin en sí mismo, que tan sólo persigue conocer al autor de la filtración (STEDH de 22 de noviembre de 2007, asunto Voskuil contra Países Bajos). Tampoco cuando no queda acreditado que se trata del único medio posible $-y$ no, como suele ser habitual, del único que se intenta- y, por tanto, que no existen otras vías alternativas a través de las cuales conocer la identidad de quien filtró la información y en su caso, perseguir el posible delito en que haya podido incurrir sin necesidad de quebrar el derecho del periodista a no desvelar la identidad de su fuente [Ernst y otros contra Bélgica; Saint-Paul Luxembourg S.A. contra Luxemburgo; y Martin y otros contra Francia (STEDH de 12 de abril de 2012)], teniendo en cuenta además que corresponde a las autoridades y no al periodista demostrar la inexistencia de estos otros mecanismos o su ineficacia para el fin pretendido.

\section{La afectación del secreto periodístico requiere la previa intervención de un juez}

A los requisitos que acabamos de ver, el TEDH ha añadido otro adicional, cuando se trata del registro e incautación de documentación, materiales e instrumentos de trabajo pertenecientes al periodista: su control judicial previo. De este modo y siguiendo la doctrina del TEDH (Sanoma II; Telegraaf Media Nederland Landelijke Media B.V. y otros contra 
Holanda) toda medida de registro y/o incautación de documentación, materiales y/o instrumentos de trabajo de un periodista requiere de la previa intervención de un juez. Lo que significa que su adopción ha de estar controlada por un órgano judicial o en su defecto por un órgano de decisión, independiente e imparcial del ejecutivo y de las partes interesadas, investido en cualquier caso, de la facultad de valorar todos los intereses en juego y, con capacidad para rechazar el requerimiento hecho por las autoridades o, en su caso, con la de emitir una orden con un alcance más limitado y restringido. Se trata así de evitar que una medida como el registro del domicilio u oficina del periodista con la consiguiente incautación de documentación, que en principio puede ser legítima, se utilice de manera arbitraria para interferir en el correcto ejercicio de un legítimo derecho: el de mantener en secreto la identidad de las fuentes informativas. Además, se trata de un control necesariamente previo, sin que se entienda cumplido cuando se realiza a posteriori, una vez que la policía u órganos administrativos de que se trate han tenido acceso a la documentación incautada. Sólo razones de urgencia podrían justificar que este control se realice en un momento posterior y aun así, deberá efectuarse antes de que el material incautado sea consultado y utilizado. Tampoco basta con que el control que se realice sea meramente formal (Görmüs y otros contra Turquía): es preciso que el juez u órgano independiente de control efectiva y materialmente supervise y controle la medida, tomando en consideración todos los intereses implicados.

No obstante la importancia de esta garantía jurisdiccional introducida por el TEDH para el conjunto de los Estados miembros del Consejo de Europa, en el ordenamiento español esta intervención, en todo caso previa, de un juez ya viene directamente exigida por los arts. 18.2 CE y 18.3 CE, para la entrada y registro domiciliario y la intervención de las comunicaciones, también cuando afectan a periodistas.

\section{Secreto periodístico y comportamiento contrario al ordenamiento jurídico de la fuente}

El ejercicio del derecho al secreto profesional por parte del periodista requiere, obviamente, la existencia de al menos una fuente cuya identidad el periodista se niega a desvelar. ¿Qué incidencia tiene la conducta de esta fuente en el secreto periodístico? Pues bien, el TEDH ha respondido a esta cuestión, desvinculando completamente el derecho de los periodistas a acogerse al secreto profesional del comportamiento (legal o ilegal, ajustado a derecho o con quebrantamiento del ordenamiento jurídico) de la fuente que le ha proporcionado la información. En palabras del TEDH:

"el derecho de los periodistas a no divulgar sus fuentes no puede ser considerado un mero privilegio de ser otorgado o quitado dependiendo de la legalidad o ilegalidad de sus fuentes, sino que es parte integrante del derecho a la información" (Tillack contra Bélgica; Nagla contra Lituania).

Esta afirmación resulta válida incluso en aquellos casos en los que resulta claro que la fuente ha actuado de mala fe y con el propósito de causar daño, divulgando intencionadamente información falsificada, a pesar de que como reconoce el propio TEDH, aquí probablemente no se causaría un daño real al secreto periodístico (Financial Times Ltd y otros contra Reino Unido). Si bien ha precisado que esta hipótesis (la mala fe de la fuente) no puede ser tenida como regla general, salvo que concurran pruebas evidentes que confirmen que esto es precisamente lo que sucede en el caso concreto enjuiciado. En cualquier caso entiende el Tribunal que la conducta de la fuente, incluso a pesar de la importancia que pueda tener en supuestos como el anteriormente referido, nunca podrá ser tenida como determinante de la decisión que tiene que tomar el juez a la hora de decidir si debe prevalecer la orden dada al periodista para que dé a conocer la identidad de su fuente o, por el contrario, su derecho a seguir manteniéndola en secreto. Se tratará tan sólo, y así debe valorarlo el juez, de uno más entre los diferentes factores y elementos que han de ser tenidos en cuenta en el momento de ponderar los diferentes derechos e intereses confrontados (Financial Times Ltd y otros contra Reino Unido).

\section{Secreto profesional, deontología periodística y veracidad informativa}

Entonces, si el hecho de que el periodista esté efectivamente protegido por el secreto periodista y pueda por tanto negarse a identificar a su fuente no depende del previo comportamiento de ésta, ¿de qué lo hace? ¿A qué aparece subordinado? A que los periodistas, al publicar esa información basada en la proporcionada por las fuentes anónimas y ahora cuestionada, hayan actuado de buena fe, publicando informaciones fiables y precisas, respetando la deontología periodística [Fressoz y Roire contra Francia (STEDH de 21 de enero de 1999); Martin y otros contra Francia; Financial Times Ltd y otros contra Reino Unido; entre otras], en relación con lo cual cobran especial importancia los pasos dados por el periodista para comprobar la exactitud y precisión (accuracy) de la información.

El hecho de acogerse al secreto profesional puede dificultar al periodista acreditar la veracidad de la noticia publicada

En esta misma línea se sitúa la Constitución española al proteger no cualquier información sino tan sólo la que es veraz, lo que remite al específico deber de diligencia que resulta exigible al profesional de la información para que lo que transmita como hechos noticiables haya sido objeto de una comprobación o contraste previo con datos objetivos o con fuentes informativas de solvencia (por todas, SSTC 6/1988 y 144/1988), sin que su cumplimiento -ha precisado nuestro TC- suponga

"en modo alguno, que el informador venga obligado a revelar sus fuentes de conocimiento" (STC 123/1993). 
La veracidad de la información publicada deviene así, junto con su relevancia pública, en requisito imprescindible para que los derechos a la información y al secreto profesional del periodista prevalezcan sobre otros derechos e intereses contrapuestos (Moretón-Toquero, 2014; en sentido contrario, Fernández-Miranda-Campoamor, 1990).

Ahora bien, el hecho de acogerse al secreto profesional puede dificultar al periodista acreditar la veracidad de la noticia publicada, ello justamente al verse privado -voluntariamente, hay que decir- de una de las principales vías para ello: la relativa a la fuente y a su credibilidad. Pero ni esta dificultad ni la circunstancia de que el periodista esté ejerciendo un derecho fundamental le eximen sin embargo de esta obligación constitucional. Deberá valerse para ello de otros medios, tales como los relativos a la solvencia de otras fuentes igualmente utilizadas o la apelación a hechos y datos objetivos.

Es quizá por esta dificultad y por lo que el principio de confidencialidad de las fuentes de información periodística significa que el TEDH ha establecido que en estos casos esta labor de contraste nunca debería resultar decisiva para la decisión judicial. Antes al contrario, sólo debería ser tenida en cuenta por el juez como un elemento más de su valoración, poniéndola en contexto con los demás elementos y circunstancias concurrentes (Financial Times Ltd y otros contra Reino Unido $)^{12}$. El TEDH resulta ser así perfectamente consciente de la dificultad que esta comprobación puede entrañar para el periodista cuando se trata de información facilitada por fuentes anónimas y que normalmente sólo está disponible para un círculo restringido de personas.

\section{Secreto periodístico y responsabilidad penal de los periodistas. El delito de revelación de secretos y el "secreto de sumario"}

Por último, no queremos terminar este trabajo sin abordar siquiera sea brevemente, una cuestión de especial importancia: la relativa a cuál es la situación jurídica del periodista que publica una información declarada secreta o confidencial, especialmente en aquellos casos en los que acogiéndose al secreto profesional se niega a desvelar la identidad de la persona que se la proporcionó. ¿Cabe exigir responsabilidad jurídica a este periodista; penal incluso?

Por ejemplo, por entender que su conducta es constitutiva de un delito de descubrimiento y revelación de secretos (art. 197 del Código Penal, en adelante CP), que castiga con penas de prisión de uno a tres años y multa de doce a veinticuatro meses a quien revele o difunda datos, documentos, imágenes, correos electrónicos o similares de otros, con conocimiento de su origen ilícito y sin haber participado en su obtención (art. 197.3 CE, en su redacción actual). O si se trata de la publicación de informaciones contenidas en un sumario judicial, mediante la aplicación del art. 466.3 CP que tipifica como delito la revelación de actuaciones procesales declaradas secretas realizadas por cualquier particular que intervenga en el proceso.

Por lo que se refiere al primero de los delitos mencionados -revelación de secretos- queremos destacar aquí el acuerdo existente en la doctrina acerca de que en estos casos nos encontramos ante un genuino conflicto entre derechos fundamentales. Por un lado, los derechos a la intimidad, a la imagen, a la protección de datos personales y/o al secreto de las comunicaciones. Por otro, el derecho a comunicar y recibir libremente información, siempre que ésta sea veraz y de interés público, lo que necesariamente habrá de ser tenido en cuenta a la hora de interpretar la posible comisión de un delito de descubrimiento y revelación de secretos por parte del periodista. Es por ello que en estos casos normalmente se ha propuesto la apreciación de la eximente prevista en el art. 20.7 del Código Penal: obrar en el ejercicio legítimo de un derecho (Otero-González, 2001; Moretón-Toquero, 2014; Jorge-Barreiro, 2002), lo que excluiría la responsabilidad penal del periodista al entender que al publicar esta información no estaría sino ejerciendo legítimamente su derecho fundamental a la información [art. 20.1.d CE $]^{13}$.

Se trata por lo demás de una interpretación que ha sido recientemente avalada por la jurisprudencia del Tribunal Constitucional en su STC 24/2019, de 25 de febrero de 2019, a partir de la idea de que una misma conducta no puede ser al mismo tiempo constitutiva de un delito y ejercicio de un derecho fundamental. De la lectura de esta sentencia podemos extraer la conclusión de que en aquellos casos en los que no queda acreditado el origen ilícito de la información, dato o documento íntimo y secreto publicado por el periodista, la noticia es veraz y de interés público y además el dato, documento o similar controvertido se refiere estrictamente a los hechos noticiables, sin ir más allá, prevalece el derecho fundamental a la información, lo que excluye que el periodista pueda ser condenado penalmente por esa misma publicación.

Además el TC ha precisado que en ningún caso del silencio por parte del periodista que se acoge a su derecho al secreto profesional puede derivarse ni el origen ilícito de la información proporcionada por la fuente ni el conocimiento por parte del periodista de tal ilicitud. Se trata de circunstancias que en todo caso deberán quedar fehacientemente acreditadas precisamente por quienes lo afirman, no por el periodista. De lo contrario, subraya el TC, el secreto periodístico perdería su finalidad y razón de ser, la de servir de garantía a la libertad de información.

Por lo que se refiere al delito de revelación del secreto sumarial es preciso tener en cuenta que, de acuerdo con la jurisprudencia del $T C$, el secreto sólo afecta a las diligencias y actuaciones procesales que integran el sumario, pero no a su contenido. Esto es, no a los hechos o sucesos acontecidos en la realidad (STC 13/1985 y STC 216/2006). El periodista puede informar de los mismos siempre que su fuente de conocimiento no haya sido el sumario, sino otra diferente. Por ejemplo, porque el propio periodista se encontraba en el lugar de los hechos ${ }^{14}$. Pero incluso cuando se trata de la publicación de información que no sólo coincide, sino que efectivamente procede del secreto sumarial, la norma penal y la 
doctrina del TC lleva a entender que sólo cabe hablar de un comportamiento ilícito por parte del periodista cuando quede acreditado que ha sido él quien ha quebrantado directamente el secreto de sumario, accediendo así a la información allí contenida. Pero no cuando hayan sido otros los que han accedido de manera ilegal a la información que después han puesto a disposición del periodista (Pérez-Cepeda, 2000). No obstante, aun en caso de comportamiento ilegal por parte del periodista, difícilmente esta conducta sería subsumible en el delito previsto en el art. 466.3 CP por cuanto que allí se requiere que el quebrantamiento haya sido realizado por un particular que intervenga en el proceso, categoría que difícilmente será aplicable al periodista (Orenes-Ruiz, 2008), sino que más bien está pensada para testigos, intérpretes y/o peritos que participan en el proceso (Quintero-Olivares, 2008). En todo caso, este comportamiento del informador habría de ser reconducible al genérico delito de descubrimiento y revelación de secretos, pero no al supuesto al que hemos aludido con anterioridad, sino a aquel otro en el que es el propio periodista el que participa en la obtención ilícita de la información (arts. 197. 1 y 197. 2 del Código Penal).

De este modo, asumiendo que la información controvertida es veraz y de interés público, la línea roja que en ningún momento puede cruzar el periodista viene dada por su propio comportamiento, estándole vedado quebrantar la norma penal para tratar de hacerse con la información controvertida. Admitir lo contrario, eximir de responsabilidad penal al periodista en este supuesto equivaldría a otorgarle una suerte de impunidad penal, incompatible -por muy importante que sean las libertades de información y prensa en una sociedad democrática y por muy loables que puedan ser las intenciones del informador a la hora de hacerse con esa información-con el propio Estado de Derecho, pero sin que quepa asumir a su vez, cuando no quede suficientemente acreditado, que esto es justamente lo que ha sucedido en el caso en cuestión.

\section{Notas}

1. Ya en el asunto Barthold contra Alemania (STEDH de 25 de marzo de 1985) utiliza el TEDH la expresión public watchdog para referirse al papel de la prensa y desde entonces no ha dejado de ser una constante en su jurisprudencia (cfr. SSTEDH dictadas en los asuntos Lingens contra Austria, de 8 de julio de 1986; The Sunday Times contra el Reino Unido ( $\mathrm{n}$ - 2) y The Observer and Guardian contra el Reino Unido, ambas de 26 de noviembre de 1991; por citar sólo algunas de las primeras).

2. Cabe recordar en este sentido el caso de la filtración de la sentencia del TC sobre Rumasa cuyo contenido fue dado a conocer por el diario El país días antes de que se publicara oficialmente y que acabó dando lugar a que su director fuese llamado a declarar como testigo en el proceso judicial abierto sobre dicha filtración por la Sala $2^{a}$ del Tribunal Supremo (ver El país, días 4 y 7 de diciembre de 1983; y 22 de febrero de 1984, respectivamente). También, más recientemente y en relación con el mismo medio de comunicación, la ocasión en la que su director fue llamado a declarar por el juez de la Audiencia Nacional Pablo Ruz en relación con el caso Gürtel a propósito de los denominados papeles de Bárcenas publicados en dicho diario (ver El país, 31 de enero de 2013 y La vanguardia, 30 de marzo de 2013). En cada uno de los casos, su entonces director se acogió al secreto profesional.

3. Es lo que sucedió justamente con los periodistas que desvelaron en el diario El mundo el caso Football Leaks, así como con su entonces director y el presidente de Unidad Editorial, antes de que el juzgado dictara auto de sobreseimiento de la causa (ver, por ejemplo, El mundo, 26 de abril de 2017, así como el comunicado de la Asociación de Prensa de Madrid de 25 de abril de 2017). Lo mismo en el caso de los periodistas imputados por revelación de datos en relación con el caso Tellería, antes de que el juzgado cambiara su condición a la de testigos (ver El país, 10 y 28 de septiembre de 2010 y El mundo, 1 de octubre de 2010). También aquí, en ambos supuestos los periodistas invocaron su derecho fundamental al secreto profesional. Más recientemente, también la periodista que destapó las presuntas irregularidades del Máster de Cristina Cifuentes en eldiario.es y su director han sido llamados para declarar como imputados por un delito de revelación de secretos en relación con este asunto (ver eldiario.es, 20 de julio). A la espera de ver cómo se desarrolle judicialmente, este caso presenta sin embargo una diferencia respecto de los otros dos: aquí se conoce la identidad de la persona que proporcionó los documentos origen de la noticia.

4. Fue el caso por ejemplo de los dos directivos de la Cadena Ser condenados por un Juzgado de lo Penal de Madrid en 2009 por publicar una lista con los datos de las afiliaciones irregulares al Partido Popular en una localidad de Madrid. Condena que después sería anulada por la Audiencia Provincial de Madrid. También del director del diario digital leonoticias.com por publicar que la entonces Presidenta de la Diputación Provincial de León cobraba indebidamente dietas por desplazamiento en vehículo particular acompañado del extracto bancario en el que quedaba acreditado dicho cobro. Condena que también sería anulada posteriormente; en este caso, por el TC muy recientemente (STC 24/2019).

5. Caso del registro de las sedes Europa Press Baleares y Diario de Mallorca ordenado por un juzgado de instrucción de Palma para decomisar los ordenadores y móviles de varios periodistas en el marco de la investigación del caso Cursach (ver 20minutos.es, 11 de diciembre de 2018).

6. Es el caso por ejemplo del auto de la Audiencia Provincial (en adelante, $A P$ ) de Tarragona 212/2004, de 13 de abril; o del auto de la AP Madrid 5955/2009, de 7 de mayo; o del auto de la AP de Vitoria-Gasteiz 10/2011, de 15 de septiembre; 
o más recientemente, del auto de la AP de Tarragona 832/2016, de 30 de septiembre, que en mayor o menor medida citan diversas SSTEDH sobre el secreto profesional de los periodistas. Incluso el auto de la AP de Vitoria-Gasteiz 9/2010, de 27 de septiembre destaca

"el esfuerzo realizado por el Tribunal Europeo de Derechos Humanos para tratar de definir el derecho a la protección de las fuentes informativas en el heterogéneo marco normativo europeo".

7. Así se recoge tanto en el Código Deontológico aprobado por la Federación de Asociaciones de Periodistas de España (FAPE) como en el Código Deontológico Europeo de la Profesión Periodística.

http://fape.es/home/codigo-deontologico http://www.asociacionprensa.org/es/images/Codigo_Deontologico_Europeo_de_la_Profesion_Periodistica.pdf

8. No obstante, tanto en la Proposición de Ley sobre el Estatuto del Periodista (2004) como, en idénticos términos, en la Proposición de Ley sobre el derecho a la información y de deberes y derechos de los informadores (2008) el secreto periodístico se contemplaba como un verdadero deber jurídico para los periodistas

"Los periodistas están obligados a mantener en secreto la identidad de las fuentes que hayan facilitado informaciones bajo condición, expresa o tácita, de reserva".

Ninguna de estas dos proposiciones consiguió sin embargo culminar su tramitación parlamentaria antes de la disolución de las Cortes Generales en la Legislatura respectiva, por lo que decayeron antes de llegar a ser aprobadas.

9. Adoptada por el Comité de Ministros del Consejo de Europa el 8 de marzo de 2000.

10. Disponible en:

http://unesdoc.unesco.org/images/0024/002480/248054E.pdf

En él se destacan además las amenazas que para esta protección puede suponer -y de hecho está suponiendo ya en algunos países- la legislación adoptada para prevenir y combatir el terrorismo. Caso del Reino Unido por ejemplo, condenado recientemente por el TEDH justamente por esta razón.

11. Dispone el art. 10.2 CEDH que:

"El ejercicio de estas libertades, que entrañan deberes y responsabilidades, podrá ser sometido a ciertas formalidades, condiciones, restricciones o sanciones, previstas por la ley, que constituyan medidas necesarias, en una sociedad democrática, para la seguridad nacional, la integridad territorial o la seguridad pública, la defensa del orden y la prevención del delito, la protección de la salud o de la moral, la protección de la reputación o de los derechos de terceros, para impedir la divulgación de informaciones confidenciales o para garantizar la autoridad y la imparcialidad del poder judicial".

12. Estima aquí el TEDH que allí donde -como en el caso concreto enjuiciado- no se puede establecer con el suficiente grado de certeza que el documento filtrado no es auténtico, el dato relativo a la autenticidad o no del mismo no puede ser tenido como un elemento importante a la hora de valorar si el secreto periodístico debe ceder a favor del interés por conocer la identidad de quien ha filtrado al periodista dicho documento.

13. Incluso los tribunales han hecho uso de esta eximente para excluir la posible comisión del delito de descubrimiento y revelación de secretos por parte de un periodista o atenuar su responsabilidad penal. Cfr., en este sentido, la Sentencia del Tribunal Supremo (STS) de 18 de febrero de 1999 y el Auto de la Audiencia Provincial de Madrid 328/2009, de 7 de mayo.

14. Es lo que sucede en el caso enjuiciado en la STC 13/1985. Las fotografías controvertidas, sobre el incendio en el que había fallecido una persona y cuya investigación habría de ser declarada secreta por el juez competente, habían sido tomadas por el propio periodista en el lugar de los hechos, por tanto, antes de que se declarase el secreto del sumario y completamente al margen del mismo, sin que quepa pues hablar de que para su obtención ha sido necesario acceder al sumario declarado secreto.

\section{Bibliografía}

Carrillo, Marc (1993). La cláusula de conciencia y el secreto profesional de los periodistas. Madrid: Civitas. ISBN: 8447001717

CEC (1988). El secreto profesional de los periodistas. Debate con Juan Luis Cebrián. Madrid: Centro de Estudios Constitucionales. ISBN: 8425907918

Fernández-Miranda-Campoamor, Alfonso (1990). El secreto profesional de los informadores. Madrid: Tecnos. ISBN: 84 30919376

Jorge-Barreiro, Agustín (2002). "El delito de descubrimiento y revelación de secretos en el Código Penal de 1995. Un análisis del artículo 197 del CP". Revista jurídica de la Universidad Autónoma de Madrid, n. 6.

https://revistas.uam.es/revistajuridica/article/view/6240

Lazkano-Brotóns, Iñigo (2004). “La protección de las fuentes periodísticas en el sistema europeo de derechos humanos”. ZER-Revista de estudios de comunicación, v. 9, n. 16.

https://www.ehu.eus/ojs/index.php/Zer/article/view/5317 
Lazkano-Brotóns, Iñigo (2015). “Artículo 10. Libertad de expresión”. En: Lasagabaster-Herrarte, Iñaki (dir.). Convenio Europeo de Derechos Humanos. Comentario sistemático. Madrid: Cívitas, pp. 510-626, ISBN: 9788447052028

Moretón-Toquero, María-Aránzazu (2012). El secreto profesional de los periodistas. De deber ético a derecho fundamental. Madrid: Centro de Estudios Políticos y Constitucionales. ISBN: 9788425915529

Moretón-Toquero, María-Aránzazu (2014). “La protección de las fuentes de información. La integración del modelo español con la jurisprudencia del TEDH". Estudios de Deusto, v. 62, n. 2, pp. 121-144.

http://revista-estudios.revistas.deusto.es/article/view/253/403

Orenes-Ruiz, Juan-Carlos (2008). Libertad de información y proceso penal. Los límites. Cizur Menor: Aranzadi. ISBN: 978 8483556290

Otero-González, María-del-Pilar (2001). Justicia y secreto profesional. Madrid: Editorial Universitaria Ramón Areces, ISBN: 8480044705

Pérez-Cepeda, Ana-Isabel (2000). Delitos de deslealtad profesional de abogados y procuradores. Cizur Menor: Aranzadi. ISBN: 8484106020

Queralt-Jiménez, Argelia (2008). La interpretación de los derechos: del Tribunal de Estrasburgo al Tribunal Constitucional. Madrid: Centro de Estudios Políticos y Constitucionales. ISBN: 9788425914317

Quintero-Olivares, Gonzalo (2008). “Capítulo VII del Título XX del Libro II del Código Penal: De la obstrucción a la Justicia y la deslealtad profesional”. En: Quintero-Olivares, Gonzalo (dir.). Comentarios al Código Penal, Tomo III, 5a ed., Cizur Menor: Editorial Aranzadi. ISBN: 9788483558935

Saiz-Arnaiz, Alejandro (2009). “Art. 10.2. La interpretación de los derechos fundamentales y los Tratados Internacionales sobre derechos humanos”. En: Casas-Baamonde, María-Emilia; Rodríguez-Piñero-Bravo-Ferrer, Miguel (dirs.). Comentarios a la Constitución Española. Madrid: Fundación Wolters Kluwer. ISBN: 9788493681203

Unesco (2017). Protecting journalism sources in the digital age. ISBN: 9789231002199

http://unesdoc.unesco.org/images/0024/002480/248054E.pdf

Villaverde-Menéndez, Ignacio (2009). “Artículo 20.1.A) Y D), 20.2, 20.4 y 20.5. La libertad de expresión”. En: Casas-Baamonde, María-Emilia; Rodríguez-Piñero-Bravo-Ferrer, Miguel (dirs.). Comentarios a la Constitución Española. Madrid: Fundación Wolters Kluwer. ISBN: 9788493681203

Voorhoof, Dirk (2009). "Freedom of expression under the European human rights system - from Sunday times (N. 1) v. U.K. (1979) to Hachette Filipacchi Associés (Ici Paris) v. France (2009)". Inter-American and European human rights journal, v. 2, n. 1-2, pp. 3-49.

\title{
Colección EPI Scholar
}

\section{Libros científicos de Información, Documentación y Comunicación}

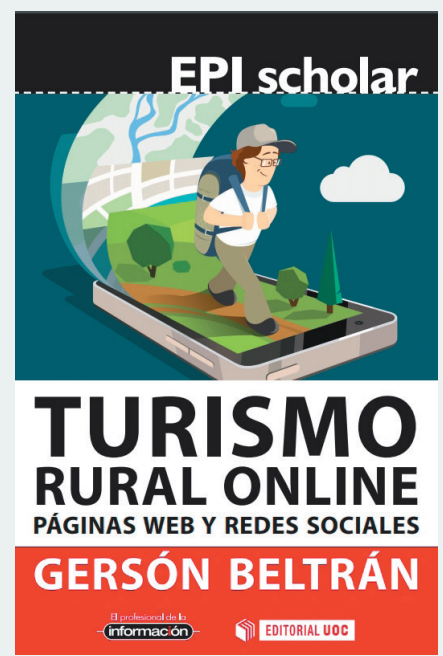

\section{Turismo rural online. Páginas web y redes sociales de Gersón Beltrán}

Los turistas están conectados en todo momento y se mueven en un entorno social, local y móvil: buscan información en internet antes de ir a su destino y realizan las reservas por anticipado, utilizan el móvil durante su experiencia turística para comunicarse y, tanto durante como tras el viaje, comparten sus opiniones en medios sociales.

Las empresas y destinos turísticos deben adaptarse a esta realidad, en la que lo físico es inseparable de lo online, conformando un entorno híbrido. Paralelamente, los espacios rurales sufren numerosos problemas de desarrollo y despoblación, y el turismo rural constituye una actividad que puede ayudar a revertir esta situación. Las nuevas tecnologías se configuran como herramientas que unen a los turistas conectados con estos espacios.

Este libro ofrece una visión general de la situación del turismo rural online, así como las claves para que las empresas y destinos turísticos logren conectar con los turistas y éstos disfruten de las experiencias únicas que les ofrece el turismo rural.

Beltrán, Gersón (2019). Turismo rural online. Páginas web y redes sociales. Barcelona: El profesional de la información, Editorial UOC, colección EPI Scholar n. 11, 170 pp. ISBN: 9788491803881

\author{
Información \\ http://www.elprofesionaldelainformacion.com/librosEPIScholar.html
}

